\title{
EVALUATING COMPETENCIES OF GRADUATES IN TOURISM AS A PREREQUISITE FOR FUTURE EMPLOYABILITY
}

\section{Lukáš Malec, Alžbeta Királováa}

\begin{abstract}
This study attempted to evaluate the differences between bachelor and master requirements in the field of tourism regarding sixteen communication as well as sixteen managerial competencies explored in a wide range of employers in the Czech Republic. The questionnaire survey data were processed using a multivariate approach of the Fisher linear discriminant analysis (LDA) and its partial least squares algorithm (plsLDA) considering two-set cases and the functional relation of both methods depending on a parameter. It was revealed that although the differences between bachelor and master requirements in communication competencies are more pronounced considering the results of the classical approach to discriminant analysis, this is not the case in its partial least squares variant. The differences are to a great extent variable, filling the whole set of individual competencies. However, the most significant competencies demanded from master graduates are: providing a complex view - summary, providing feedback, time management, leadership and planning, considering both boundaries of eigenvalues with corresponding eigenvectors analytical (resp. smooth) path. The practical implication of the results can serve as a target for modern educational systems preparing students for success in the current competitive environment.
\end{abstract}

Keywords: Fisher discriminant analysis, partial least squares variant, eigenvalue paths, communication and managerial competencies, employability of graduates, tourism

JEL Classification: C30, C50, J20

\section{Introduction}

Education of the population has a significant impact on employability, and the global economic crisis has seriously increased the effect. The crisis period has also demonstrated that a quality education can compensate for the lack of work experience. Employability is generally considered a competitive advantage, especially in developed economies (Brown and Lauder, 1996). In case of unemployed graduates, this becomes a very expensive service financed by individual exchequers with varying conditions over individual regions. According to the Organisation for Economic Cooperation and Development (OECD, 2013), the opinion of many employers can be expressed in the way, that the education systems "educate graduates of tomorrow in the skills needed in the sector yesterday". Employers also express their beliefs as graduates undervalue soft competencies, such as communication, managerial, personal and problem-solving abilities. There emerges a need to better fit

* Lukáš Malec, Department of Information Technologies and Analytical Methods, University of Business in Prague, Prague, Czech Republic (malec@vso-praha.eu);

Alžbeta Királ'ová, University of Business in Prague, Prague, Czech Republic (kiralova@vso-praha.eu). 
a general set of competencies to the society and the economy, and to identify competency issues that may occur in a competitive environment. In the Czech Republic as well as in many other Central and Eastern European countries, the lack of soft competencies tends to be more pronounced (CEDEFOP, 2014). Based on such prerequisites and in the view of the recent global economic crisis, this has also influenced education in the context of real occupations. In the Czech Republic, one in five graduates works in another field of study - four to five years after graduation. In a time of modern educational systems and information technologies, the target of university education should be focussed on graduates' success in entering the labour market. This current situation forms the background to accelerating the development of transferable competencies that are more general and that can be applied in various areas of employment.

Employability is generally affected by a number of external factors given by economic and labour market conditions. Researchers at the National Institute of Vocational Education in the Czech Republic found that while the number of higher education graduates is forecast to increase about by $43 \%$ from the year 2013 to 2020 , the number of jobs will increase only about by $10 \%$ (Hruška, 2013). Jobs requiring a university degree are estimated to comprise $25 \%$ of all jobs in the Czech Republic by 2020 (Kejhová, 2011). In recent years, there has been indicated an increase of about 10000 graduates per year, while nearly threequarters of bachelor students continued on to masters studies.

Tourism and tourism-related activities have a positive impact on economic growth of individual territories, they are largely labour intensive and as a whole often an indicator of crisis periods, see, e.g. (Smrčka, Arltová and Schönfeld, 2011). Despite some negative effects, such activities substantially increase the level of education. Based on the Czech Statistical Office data (CZSO, 2015) tourism is not a dominant industry in the Czech Republic (almost 3\% of GDP given by the tourism satellite account methodology) although a significant one. Considering this fact, some Czech business and economic institutions offer the tourism branch as the undergraduate specialization. Universities focus on the professional knowledge as well as job-specific competencies and communication while considering the full educational spectrum of subjects as an aim of national higher educational systems. There are many quality assessment efforts within the OECD countries considering learning outcomes like knowledge and competencies. In the European Qualifications Framework, the learning outcomes are defined as "statements of what a learner knows, understands and is able to do on completion of a learning process" (EC, 2006). In the real educational conditions, passing an exam can be perceived as "ability to master the subject in a limited time interval". As an example, the engineering graduates express their opinion as professional education programmes provide formal credentials used in the scope of potential employers providing graduates capable to hard work, rather than being equipped with competencies straightforwardly applicable in practice (Nilsson, 2010). The future demands considering e.g. the lifelong learning are also important.

The efforts to create a common European Higher Education Area as a goal of the Bologna Process were initiated in 1999. The target is introducing the system of bachelor's and master's degrees mutually and quantitatively comparable within European institutions with variable 
implementation opinions (Sinz, 2009). According to the Czech Republic Act No. 137/2016 Coll. of 1 September 2016, National Accreditation Authority with submitted state approval is the main body in current two accreditation possibilities, i.e. institutional accreditation and study programme accreditation. In the light of the Bologna Process and the new Czech Ministry of Education, the Youth and Sports programmes, the communication and managerial competencies can play an important role in future university school systems evolution. Also current highly competitive environment can appreciate future employers due to be confident with strong qualifications in skills and knowledge of the individual programme graduates. The prestigious international accreditations in business expressed briefly as ACBSP, AACSB, EFMD-EPAS and IACBE form a substantial and solid base for considering the results of this study. Such prestigious accreditations are in the Czech Republic currently awarded at the University of Economics, Prague, the Anglo-American University in Prague, the University of Pittsburgh, the Prague Campus, the Škoda Auto University, the University of Economics and Management and University of New York in Prague.

Employer's requirements regarding the various forms of competencies seem to be crucial in the educational systems and in securing human capital when currently unemployment financed from public budgets is very expensive service with an increasing tendency. Communication and managerial competencies are the most important soft competencies in the tourism. Due to growing interest in graduate employability there emerges the strong demand for more research to better fit and to improve competency development within the educational sector. This empirical study fills a gap given by the lack of the literature, dealing with two-set data considering differences between demands on bachelors and masters graduates by separately analysing their competencies. From master graduates original communication competencies the results indicate the most demanded "providing a complex view - summary", "providing feedback", "knowledge of the issues" and "ability to talking and conversation". In the case of managerial competencies, "time management", "leadership", "ability to handle conflicts", "planning", "managing stress" and "problem solving" are the most required from master graduates as opposed to bachelor ones.

The multivariate range of methods was used in this study, i.e. Fisher linear discriminant analysis (also the so called Fisher discriminant analysis) and principal component analysis (PCA) supplemented by descriptive statistic outputs. Fisher discriminant analysis was extended by analytical paths of eigenvalues and eigenvectors to originate the other boundary point corresponding to its partial least squares variant derived likewise the connection of canonical correlation analysis and partial least squares (Malec, 2016) with various statistical properties of its boundaries, see e.g. the studies by Wegelin (2000) or Malec (2013). The plsLDA approach based on learning the weighted squared deviations of linear combination means from the grand mean is particularly suitable for a small-sample problem and in the case of collinearity or near-collinearity within sets.

\section{Competency literature review}

There exist many definitions of the term competency, see e.g. (Boyatzis, 1982; Kessler, 2006; Kessler and Strasbourg 2005; EC, 2007). These definitions can be summarized as 
a "set of personal characteristics, attitudes, knowledge and skills leading to high-quality performance". Knight and Yorke (2004) proposed four main competency fields fitting the graduate employability area as understanding (control of the subject), skilfulness (generic and subject-specific area), efficacy beliefs and metacognition (knowledge of ones' acting). Often, the satisfaction is not identified from the side of employers, e.g. considering the key generic competencies such as non-technical or soft ones (Azevedo, Apfelthaler and Hurst, 2012). The growing emphasis is moreover placed on generic skills due to its connection with being adaptable and flexible in the current labour market.

Boyatzis (1982), Kessler and Strasbourg (2005) and others consider competencies essential to attaining a job and to keeping employment in the future. Job attainment, salary increases and a reduced risk of dismissal rise with the level of competency (Orazem and Vodopivec, 1997). Considering the relationships to other employers, there are recognized core competencies (Belz and Siegrist, 2001), general and specific competencies, basic and high performance competencies (Schroeder, 1989), and basic and threshold competencies (Boyatzis, 1982; Balcar, Janíčková and Filipová, 2014). More specifically, the general and specific competencies can be in many cases straightly distinguished between in the labour market. While the general ones can be adopted in case of almost any job, the specific competencies (often involving more in-depth and complex knowledges) are suitable only for applying in the particular environment. From this reason, the situations considering the loss of a job is more likely to be solved using a set of general knowledges. The increased number of university graduates in the changing economic climate means that a degree does not guarantee a future career. Moreover, Drucker (1993) and Stewart (1997) express the opinion that knowledge is more significant and powerful than natural resources or capital. In a study conducted at the California State University in Sacramento, which established a basic methodology as well, faculty expectations and selected significant employers' communication curriculum was set to establish course objectives, faculty evaluation and a method for determining course outcomes (Estenson, 1999).

Communication and managerial competencies are one of the basic parts of requirements in the tourism sector. Due to recent transformations in media and related fields which enable organizations to engage in symmetrical communication, current practitioners also desire theses competencies in various modern areas, such as strategic planning, measurement/evaluation and cultural awareness, as well as requiring the ability to be flexible and collaborative (Flynn, 2014). Communication competencies consider all mental conditions that allow a person to be able to communicate and evaluate the other persons involved in the communication process. Spitzberg (1988, p. 68) expressed the communication competency as "the ability to interact with others". In addition to that, communication competencies are defined as a part of an individual's social competencies. On the other hand, managerial competencies are defined as the behaviour to demonstrate effective performance within the occupational area, and leading to competently mastered tasks (Woodruffe, 1992; Rankin, 2004). Application of managerial competencies may result in effective performance within the organization.

In the work of Azevedo, Apfelthaler and Hurst (2012) considering Austria, the UK, Slovenia and Romania joined project, they describe the eight key generic competencies 
(threshold ones required to appropriately practice a job) that were evaluated as "influencing and persuading", "teamwork and relationship building", "critical and analytical", "self and time management", "leadership", "ability to see the bigger picture", "presentation" and "communication". As the processing methods of choice were selected non-parametric Kruskal Wallis analysis of variance test, exploratory form of factor analysis, and PLS path modelling approach. The high and similar competency within-country rating was identified as "communication", "teamwork and relationship building" and "self and time management". On the other hand, "leadership" and "presentation" are the lowest ranked positions. The capabilities evaluated are in contrast to preceding which consider "leadership", "presentation" and "ability to see the bigger picture". Although some limitations as not to investigate also the difference between excellent performers from the average ones, such a study considers the deep insight into undergraduate performance. In the work dealing with undergraduate and graduate students at the College of Business at Texas A\&M University they reveal "integrity/honesty" and "good work ethic" as the highest factors evaluated by both groups (English et al., 2012). Generally, they detect the intrinsic qualities of the individual as the highest ranked workplace quantities, while the external experiences were evaluated as the lowest.

Balcar, Janíčková and Filipová (2014) using probit regression and descriptive approach examine general competencies on the basis of job advertisements published online and test the presumption if the demand is really general or differs with other conditions as education or firm characteristics. They identified at least one foreign language (especially English) demand for which is growing with the education level. Information technologies skills are also proven very important. Employer's requirement regarding soft competencies considers "communication and presentation", "responsibility, reliability and diligence", "independence", "flexibility and cooperation" and "team work" as the most required differing on the level of education. More specifically, the competencies "cooperation and team work" and "organizing, planning and leadership" are mainly required from university graduates.

\section{Experimental}

\subsection{Data used}

A questionnaire targeted for assessing the difference between requirements on different educational levels forms the data source used in this study carried out between March and June 2014. A sample of 126 employers in the Czech Republic constitutes the database. Due to the highly specialized population oriented exclusively on tourism, we accept the presumption of proper generalization the results on whole structure of the targeted industry. Respondents were selected in the way as being random representatives of companies in the Czech Republic under the European Company Database (EURODATA, 2014) and the Czech Statistical Office (CZSO, 2014) as a whole spectrum of stakeholders in the tourism industry extended by government and public administration entities. The destination management members are also a part of the sample. The questionnaire response rate was relatively high with almost $80 \%$ of properly completed forms. In order 
to ensure a diverse group of respondents, the targets in this study included hotels, catering companies, transportation companies, travel agencies and tour operators, event agencies, ministries, regional authorities, municipalities and municipal authorities, chambers of commerce, destination management organizations, tourist information agencies, spas, adventure agencies, heritage associations, attractions, and water parks. All the responses in the structured questionnaire, except for characteristics of the respondent, were rated on a ten-point Likert scale. Respondents include directors, various managers, HR officers, councillors and assistants. It was revealed that approximately $17 \%$ represented staff with more than 100 employees.

The data on communication and managerial competencies were processed separately for analysing differences in bachelor and master graduation levels. The selection of individual competencies undergoes the long process comprising a detailed analysis of academic literature as well as number of preliminary quantitative interviews with stakeholder representatives. Based on a study by Királ'ová and Malec (2014), the 16 communication and 16 managerial competencies (variables) were selected as the most independent from the original counts of 32 and 40, respectively, based on outputs from the principal component analysis processing the original data.

\subsection{Methods}

Current multivariate processing approaches in tourism considering data from questionnaires with various forms of Likert scale measures are predominantly orientated to factor analysis and structural equation modelling. In the following we concentrate our attention on the studies not mentioned previously. An example of resource capabilities in the hotel industry can be demonstrated by Ramanathan and Ramanathan (2013) and Chand and Katou (2007). In the study (Ramanathan and Ramanathan, 2013), the authors examine online ratings for the UK hotels with the aim to assess the intention of customers to revisit the hotel and recommend the service to friends. On the other hand, Chand and Katou (2007) use a self-administered questionnaire on 27 human resource practices, 5 organizational performance variables, and 10 demographic variables to assess whether a positive relationship between organizational performance and specific characteristics of hotels exists, and if a connection between the human resource management systems and organizational performance can be revealed. Customer retention in Thailand, in the sense of revisiting the destination, is studied by Ngamsom (2001) using a sample of international travellers checking in for the departure to select inbound markets. In the studies (Van Dyne, Ang and Koh, 2008; Mahembe and Engelbrecht, 2014) the cultural intelligence scale is analysed using questionnaire surveys. Van Dyne, Ang and Koh (2008) used a factor analysis and confirm a four-factor structure of relations based on business school undergraduates in Singapore. Then the good fit to data was proven using a structural equation modelling approach. In the psychometric study (Mahembe and Engelbrecht, 2014), the construct validity of the cultural intelligence scale was assessed with significant insight to the factor structure of the problem and proof of the scale as a reliable and valid measure for cultural intelligence. 
In this study, we use two multivariate methods, i.e. LDA and principal component analysis. The task of Fisher discriminant analysis is to characterize the differences between sets of quantitative data by their projection to space of lower dimension. This fundamental method is based on searching for linear combinations of original variables (discriminant variates), which maximize the difference between the sets at simultaneous encompassing specific within-sets property which, in whole, is a straightforward exercise in calculus (Krzanowski, 2000, pp. 294-296). We describe and apply standard Fisher linear discriminant analysis and the variant considering its analytical (thus also smooth) paths of eigenvalues and corresponding eigenvectors depending on a parameter with one boundary point describing only the between-sets mean differences. Due to better interpretability of results, the coefficients are first rescaled as within-sets variance of linear combinations equals 1 considering a parameter process, and then to unit norm a posteriori in all cases. The one boundary point of functional relation corresponds to Fisher discriminant analysis and the other one to its partial least squares variant of which eigenvector elements in the case of two sets express the differences in individual variable means between the sets. Thus, considering our particular case, the Fisher discriminant analysis can be expressed almost entirely as an analytical path of the mean differences between sets. Also the process of functional relation was studied representing some typical property of the paths. Although in the case of two sets, the plsLDA method is computationally simple due to the existence of short formulas, the comparison with Fisher linear discriminant analysis as well as studying the functional relation using the analytical (thus also smooth) paths of both methods can serve as a useful tool in practical data processing situations. It is interesting to see the solutions of both spectral and short formulas are coincident, i.e. leads to the same algorithms in our specific two-set case based on the works of Janovská, Janovský and Tanabe (2008), Janovská and Janovský (2010) and Harville (1997), together with the fundamentals in multivariate analysis (see Appendix).

Like a standard analysis of variance approach, where the differences between set means are reduced by individual variable variances, in Fisher discriminant analysis, the multivariate differences are influenced by variances, but also by covariance relations within the sets of data. We define functional relation to the other alternative of Fisher discriminant analysis, termed here as its partial least squares variant. In contrast to Fisher linear discriminant analysis, the partial least squares algorithm is strictly reduced to learning the weighted square deviation of discriminant variate means in all the sets from their grand mean without the influence of any additional constraints. The presented study considers a simplified computational representation as analysing two-set matrices and the weights in both sets equal due to the same number of observations. Because the number of original variables highly exceeds the number of sets, the between-sets covariance matrices are singular and the only first eigenvalues nonzero.

There are many approaches to partial least squares discriminant analysis, see e.g. (Barker and Rayens, 2003; Pérez-Enciso and Tenenhaus, 2003). In the study of Barker and Rayens (2003), the discriminant analysis is studied on the modified form of between-sets covariance matrix considering some constraints. This is particularly important for our study due to a close connection to LDA partial least squares variant originating as the degree 
of constraints on within-sets covariance matrix augmenting in the paths of Fisher discriminant analysis. The plsLDA approach, or potentially the solution close to this boundary point, considering functional relation of both studied methods, is especially suited for a smallsample problem when the number of observations is less than the number of variables, and in the case of collinearity or near-collinearity within sets. Specifically, in this study, the functional relation examines the analytical (thus also smooth) paths of eigenvalues and corresponding eigenvectors solving the Fisher discriminant analysis (Malec, 2015). Malec (2016) compares canonical correlation analysis and partial least squares considering also their kernelized versions which relation was derived in a similar way as among discriminant analysis methods used in this study. Some preliminary notes are also mentioned in (Malec and Malec, 2013). Robustness is the other task which can be possibly examined in the scope of above mentioned approaches, see e.g. (Kalina, 2012). As an auxiliary method, PCA was used to select the subset of original variables, to study the interrelationships within the sets and for measuring the elements of eigenvectors path degree of similarity.

Pre-processing the data is the first step in our approach. Before the analyses, the sample skewness and kurtosis of variables were studied. Because of negatively skewed data and also its heteroscedasticity, the Box-Cox transformations were applied prior to the analyses (Hossain, 2011; Seaks and Layson, 1983). Using the maximum likelihood method, the mean value of the transformation parameter 2.18 was estimated and applied to all variables describing the communication domain. Considering managerial competencies, the approximate mean value of the Box-Cox transformation parameter 2.42 was calculated in the same way, and the data were treated correspondingly. Although we follow the descriptive approaches with no other inferential aspects with regard to the transformed data, the hypotheses on equality of covariance matrices by Bartlett's modification of the likelihood ratio test were processed as an essential prerequisite for applying the standard Fisher linear discriminant analysis. In both cases, the hypothesis was not rejected considering a 5\% significance level. The bootstrap procedure was used to obtain corresponding $p$-values of 0.173 for communication competencies and 0.085 for managerial ones.

The analyses were performed using the Matlab 7.1 (Mathworks, Natick, MA, USA) software platform by its Statistics toolbox and an own written programs.

\section{Results and Discussion}

We evaluate input data matrices by introductory descriptive statistic, an analysis of relations, as well as searching the difference measures between individual sets. From Table 1 on raw data it is evident that on average the master competencies requirements are more in demand, with only one exceptional variable "explanation and analysis of the results" at communication competencies. This difference is not significant to a great extent. At managerial competencies, the mean differences are more pronounced as opposed to communication ones, but the variances of the individual variables as well. On average, the most generally demanded are the communication competencies as "electronic communication", "providing a complex view - summary", "accurate, clear and understandable expression" and "knowledge of the issues". For testing within-sets relations, the principal component analysis using covariance matrix 
of the transformed data was accommodated, where at communication competencies, the first principal component shares $41.44 \%$ of variance for bachelors and $39.04 \%$ for masters. In the case of managerial competencies, the first principal component shares $48.05 \%$ of variance for bachelors, and for masters, the share is $53.56 \%$.

Table 1 | Communication and Managerial Competencies - Descriptive Characteristics

\begin{tabular}{|c|c|c|c|c|c|c|c|c|}
\hline & \multicolumn{4}{|c|}{$\begin{array}{l}\text { Communication } \\
\text { competencies }\end{array}$} & \multicolumn{4}{|c|}{$\begin{array}{c}\text { Managerial } \\
\text { competencies }\end{array}$} \\
\hline & \multicolumn{2}{|c|}{ Bachelors } & \multicolumn{2}{|c|}{ Masters } & \multicolumn{2}{|c|}{ Bachelors } & \multicolumn{2}{|c|}{ Masters } \\
\hline & mean & variance & mean & variance & mean & variance & mean & variance \\
\hline 1 & 7.882 & 2.235 & 8.294 & 0.971 & 7.353 & 3.762 & 7.471 & 5.025 \\
\hline 2 & 7.765 & 4.289 & 8.529 & 3.756 & 6.941 & 5.184 & 7.529 & 6.890 \\
\hline 3 & 8.706 & 1.596 & 9.000 & 1.500 & 6.118 & 5.360 & 7.235 & 6.316 \\
\hline 4 & 7.294 & 1.721 & 7.529 & 1.265 & 5.353 & 6.993 & 7.701 & 3.971 \\
\hline 5 & 6.294 & 2.221 & 7.000 & 3.000 & 5.647 & 6.118 & 7.618 & 3.360 \\
\hline 6 & 7.018 & 4.437 & 7.941 & 2.078 & 6.235 & 9.357 & 8.588 & 6.471 \\
\hline 7 & 8.000 & 1.250 & 8.647 & 1.243 & 6.353 & 5.495 & 8.353 & 4.279 \\
\hline 8 & 7.353 & 1.243 & 8.412 & 1.382 & 5.471 & 7.890 & 7.941 & 4.434 \\
\hline 9 & 6.765 & 4.441 & 7.118 & 7.610 & 6.177 & 6.904 & 7.706 & 4.721 \\
\hline 10 & 8.471 & 0.765 & 8.706 & 1.221 & 7.235 & 4.534 & 8.549 & 3.795 \\
\hline 11 & 8.483 & 2.515 & 8.706 & 1.971 & 7.089 & 5.684 & 8.588 & 3.943 \\
\hline 12 & 6.294 & 2.721 & 7.353 & 2.868 & 7.059 & 6.957 & 8.529 & 5.346 \\
\hline 13 & 7.000 & 2.875 & 7.941 & 3.434 & 5.941 & 6.522 & 7.705 & 5.396 \\
\hline 14 & 7.706 & 5.526 & 7.059 & 7.495 & 5.118 & 7.860 & 7.531 & 7.390 \\
\hline 15 & 7.177 & 3.029 & 7.824 & 4.529 & 5.765 & 5.189 & 7.765 & 4.267 \\
\hline 16 & 7.118 & 5.423 & 8.529 & 4.854 & 6.235 & 6.589 & 8.177 & 4.392 \\
\hline
\end{tabular}

Note: The numerical values correspond to individual competencies. For the communication domain, the variables are:

$\mathbf{1}$ - Ability to talking and conversation (verbal communication), $\mathbf{2}$ - Ability to writing and fading (written communication), 3 - Electronic communication, 4 - Listening and active listening (expression of interest on partner), $\mathbf{5}$ - Ability to use non-verbal signals adequately, $\mathbf{6}$ - Communication by action, $\mathbf{7}$ - Providing a complex view - summary, 8 - Providing feedback, 9 - Asking the checking questions, 10 - Accurate, clear and understandable expression, 11 - Knowledge of the issues, 12 - Persuasion, 13 - Argumentation pros and cons, 14 - Explanation and analysis of the results, 15 - Discussion and negotiation, 16 - Fluent written and spoken communication in a foreign language.

The managerial competencies consider:

1 - Self-motivation, 2 - Assertiveness, 3 - Capacity to take risks and evaluate risk, 4 - Leadership, 5 - Visionariness, 6 - Ability to take a decision, 7 - Planning, 8 - Delegating, 9 - Team building, 10 - Problem solving, 11 - Ability to handle conflicts, 12 - Managing stress, 13 - Ability to motivate others, 14 - Change management, 15 - Managing activities beyond routine, 16 - Time management.

Source: Authors. 


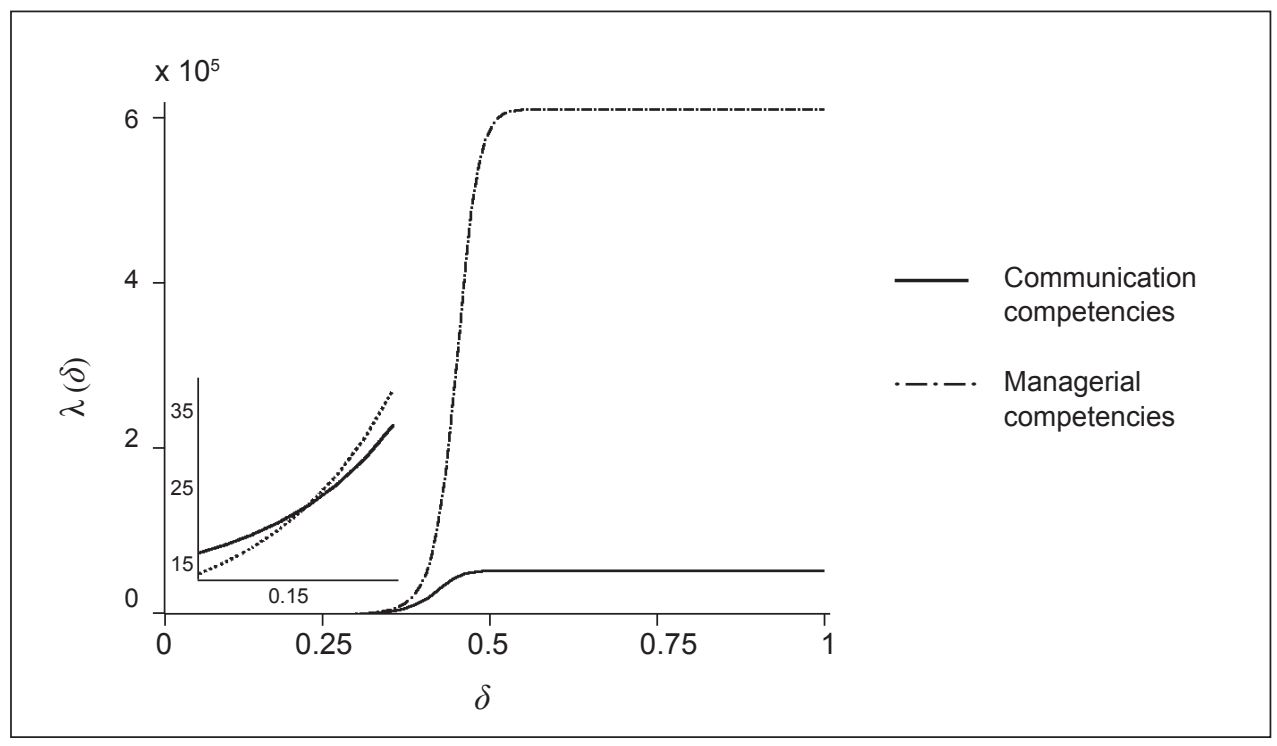

Source: Authors.

Because of the suitable character of the paths, we choose the previous step withinsets covariance matrix as input to the following step of the iteration algorithm without change in the analytical (resp. smooth) property of this matrix. In such an arrangement, the path shapes depend on the choice of step in the process $\delta \in\langle 0,1\rangle$ with constant boundary points; the step was set to 0.01 . The path of individual eigenvalues (see Figure 1) gives us very important information about the significance of communication and managerial competencies in discriminating by LDA or simple partial least squares variant of this method. The boundary points of the analytical paths give greater significance to communication competencies at Fisher linear discriminant analysis in contrast to managerial competencies where the eigenvalue was very high at plsLDA in comparison to Fisher discriminant analysis. This reveals an information that although managerial competencies are more significant in discriminating the sets using only mean differences between sets, this case is very influenced by strong internal variances and also covariance relations, decreasing its significance in the standard Fisher discriminant analysis. The intersection of both eigenvalues path is identified close to the point $\delta=0.15$. We consider the LDA boundary points results as targeted because the variables initially selected by principal component analysis. Although there is some discrepancy, such as geographical position and target respondents, the results are in accordance with the study conducted by Azevedo, Apfelthaler and Hurst (2012) where the competency "communication" is high within-country ranked in the similar way as "teamwork and relationship building" and "self and time management". 
Table 2 | Communication and Managerial Competencies - Discriminant Coefficients

\begin{tabular}{|c|c|c|c|c|c|c|}
\hline & \multicolumn{3}{|c|}{$\begin{array}{l}\text { Communication } \\
\text { competencies }\end{array}$} & \multicolumn{3}{|c|}{$\begin{array}{c}\text { Managerial } \\
\text { competencies }\end{array}$} \\
\hline & LDA & plsLDA & PCAdc & LDA & plsLDA & PCAdc \\
\hline$\lambda(\delta)$ & 11.60 & $5.35 \times 10^{4}$ & 0.28 & 7.18 & $6.07 \times 10^{5}$ & 0.38 \\
\hline \multicolumn{7}{|c|}{ Coefficients } \\
\hline 1 & -0.330 & 0.131 & 0.400 & 0.241 & 0.091 & -0.123 \\
\hline 2 & 0.103 & 0.200 & 0.084 & -0.039 & 0.127 & 0.137 \\
\hline 3 & 0.007 & 0.129 & 0.127 & -0.198 & 0.186 & 0.287 \\
\hline 4 & -0.104 & 0.073 & 0.174 & 0.350 & 0.314 & -0.025 \\
\hline 5 & 0.076 & 0.245 & 0.139 & -0.188 & 0.266 & 0.342 \\
\hline 6 & 0.124 & 0.249 & 0.104 & 0.193 & 0.310 & 0.102 \\
\hline 7 & 0.609 & 0.268 & -0.278 & -0.399 & 0.295 & 0.519 \\
\hline 8 & 0.300 & 0.416 & 0.075 & 0.196 & 0.337 & 0.105 \\
\hline 9 & -0.235 & 0.197 & 0.382 & 0.021 & 0.220 & 0.171 \\
\hline 10 & -0.029 & 0.114 & 0.117 & -0.262 & 0.197 & 0.351 \\
\hline 11 & -0.531 & 0.090 & 0.545 & 0.338 & 0.235 & -0.090 \\
\hline 12 & 0.184 & 0.351 & 0.145 & -0.271 & 0.197 & 0.361 \\
\hline 13 & 0.104 & 0.358 & 0.205 & -0.157 & 0.225 & 0.296 \\
\hline 14 & -0.042 & -0.008 & 0.038 & 0.235 & 0.344 & 0.081 \\
\hline 15 & 0.028 & 0.276 & 0.237 & -0.095 & 0.247 & 0.271 \\
\hline 16 & 0.055 & 0.410 & 0.310 & 0.407 & 0.253 & -0.129 \\
\hline
\end{tabular}

Note: The numerical values correspond to individual competencies. For the communication domain, the variables are:

1 - Ability to talking and conversation (verbal communication), $\mathbf{2}$ - Ability to writing and fading (written communication), 3 - Electronic communication, 4 - Listening and active listening (expression of interest on partner), $\mathbf{5}$ - Ability to use non-verbal signals adequately, $\mathbf{6}$ - Communication by action, $\mathbf{7}$ - Providing a complex view - summary, 8 - Providing feedback, 9 - Asking the checking questions, 10 - Accurate, clear and understandable expression, 11 - Knowledge of the issues, 12 - Persuasion, 13 - Argumentation pros and cons, 14 - Explanation and analysis of the results, 15 - Discussion and negotiation, 16 - Fluent written and spoken communication in a foreign language.

The managerial competencies consider:

1 - Self-motivation, 2 - Assertiveness, 3 - Capacity to take risks and evaluate risk, 4 - Leadership, 5 - Visionariness, 6 - Ability to take a decision, 7 - Planning, 8 - Delegating, 9 - Team building, 10 - Problem solving, 11 - Ability to handle conflicts, 12 - Managing stress, 13 - Ability to motivate others, 14 - Change management, 15 - Managing activities beyond routine, 16 - Time management.

Source: Authors. 
Table 2 introduces the first-order coefficients of the Fisher linear discriminant analysis and its plsLDA variant. In the following, the elements of eigenvectors $>0.25$ are descriptively considered as significant and discussed throughout this study. The PCA coefficients are also studied, describing the similarity of Fisher discriminant analysis elements of the eigenvectors path. We abbreviate such approach as PCAdc. Empirically, because the paths of eigenvectors in discriminant analysis have only one short and well-separated disruption interval in the processes, this criterion can roughly serve to reveal the degree of complex structure especially considering the short interval.

At communication competencies, the LDA reveals the most differing for "providing a complex view - summary" and "providing feedback" in one sense and, in contrast to this, the "knowledge of the issues" and "ability to talking and conversation". On the other hand, at the plsLDA - "providing feedback", "fluent written and spoken communication in a foreign language", "argumentation pros and cons", "persuasion", "discussion and negotiation" and "providing a complex view - summary" are the most significant. Contrary to the Fisher linear discriminant analysis, all the significant coefficients at partial least squares variant have the same signs, and thus affect the differences in the same manner. In the case of LDA, the signs of individual eigenvector elements are dependent on the direction of mean differences and covariance structures which is not the case in partial least squares variant where the sign is solely given only by mean differences between sets. Also in case of plsLDA, the solution is given by the minimum norm of eigenvectors, thus the values of coefficients are not to great extent high, yet significant. "Providing a complex view - summary" and "providing feedback" variables are significant in both analyses. Specifically, in the Fisher discriminant analysis, the "providing a complex view - summary" is the most important, and considering the partial least squares variant of Fisher discriminant analysis, the most significant variable is "providing feedback".

The managerial competencies "time management", "leadership" and "ability to handle conflicts" differ most, but opposite to "planning", "managing stress" and "problem solving" for the Fisher linear discriminant analysis. In case of partial least squares variant “change management", "delegating", "leadership", "ability to take a decision", "planning”, "visionariness" and "time management" are the most significant. In both analyses, variables "leadership", "planning" and "time management" are important. Specifically, in the standard Fisher discriminant analysis, "time management" is the most significant variable, and in partial least squares variant "change management" is the most significant. The properties of outcomes from both analyses of this part are like the information introduced at communication competencies.

In the LDA results the foreign language is not targeted bachelor and master graduates difference as required in the general labour force and considering the other works, see e.g. (Balcar, Janíčková and Filipová, 2014). Also "team building” was not proven significantly different between the two sets in our study.

We also analysed the similarity of unit norm eigenvectors path between LDA and its partial least squares variant using first-order principal component analysis on the covariance measures. If predominantly, the significant changes in magnitudes of elements of eigenvectors 
between both boundary points, possibly taking into account sign difference, are mainly attended with the significant elements of eigenvectors in PCAdc, this can be a simple indication of onedirectional similarity pattern of principal shifts. If this is not the case, the significant shifts in paths cannot be explained by the only one principal direction and the behaviour inbetween both boundaries is rather complex. The communication competencies as well as the managerial competencies reveal only one predominant direction of functional pattern where all the substantial shifts are accompanied with significant, or at least close to significant, coefficients in principal component analysis. For communication competencies, the most significant in PCA is the variable "knowledge of the issues", which is the leading in the transformation shapes of functional relation. In case of managerial competencies, the leading in PCA is the variable "planning" as the most significant covering the paths.

\section{Conclusion}

The positive impact of schooling as a fundamental part of human capital on economic growth was proven by many studies where the quality and content of educational system applicable in practice considering general competencies is a significant task in addition to the length of education (Kubík, 2015). Specifically, the secondary and tertiary levels of education were detected as the most important factors. Such relationships are particularly valid in tourism industry being closely connected to humans. In the Czech Republic, the majority of education is financed from the public accounts. On the other hand, as expressed by Čadil (2011), total estimated costs from public finances on average unemployed taking into account the loss in income tax collection and social and health insurance paid are very burdensome. If we consider the total estimated costs from public budgets (on unemployed) assuming average duration of unemployment 5 months and taking into account the fact in last years that expenses gradually increase, these roughly correspond half of the annual tuition of standard private college in the Czech Republic. Specific domain covers the social economy at application of handicapped people for who the education has also its own significance. In addition to the employment policy it is important to apply the other mechanisms in the Czech Republic rather unused but demonstrating the potential in countries with similar issues.

Taking into account the average values of datasets in this study, the master competencies are generally more required with the exception of the communication variable, i.e. "explanation and analysis of the results". However, the sign difference, being the only one exception, is not proven significant in accordance with the following discriminant analyses. This situation is caused by the structure of input data, especially considering LDA results. Generally, the communication competencies "electronic communication", "providing a complex view - summary", "accurate, clear and understandable expression" and "knowledge of the issues" are the most required considering results of the descriptive statistic.

Quality in higher education has been recently under a significant attention with many ideas and suggestions how the quality can be defined in the educational context. Knowledge of employers' demands on competencies is very important in the scope of human capital accumulation. The main results of this study report some interesting specific outcomes not 
well addressed in literature as follow the distances between bachelor and master requirements in tourism. Due to the initial selection of communication and managerial variables from the original counts exceeding 30 considering both cases, the Fisher discriminant analysis can be accepted as a method of choice with some additional information given by its partial least squares variant. Moreover, the plsLDA approach is closer to a simple descriptive approach considering only the between-sets covariance matrix. It was revealed by the eigenvalues path that communication competencies are more significant in discriminating the sets of bachelor and master requirements using the standard approach as opposed to the managerial one. This is particularly interesting fact the communication skills are more different. Apparently master graduates gained positions in middle or even in higher management so their focal point consists primarily in communication with subordinates considering e.g. a strategic marketing and not in communication with guests (customers or visitors). From this reason are the requirements for communication competencies relatively high distant.

Considering all the original communication competencies in this study - "providing a complex view - summary", "providing feedback", "knowledge of the issues" and "ability to talking and conversation" are the most required from master graduates, with the first two mentioned variables particularly significant as supported by LDA partial least squares variant. Study of the managerial competencies reveals the variables "time management", "leadership", "ability to handle conflicts", "planning", "managing stress" and "problem solving" the most demanded from master graduates as opposed to bachelor ones. Here, the variables "time management", "leadership" and "planning" are the ones supported also by considering the results of plsLDA. The leading pattern of eigenvectors path is given by the variables "knowledge of the issues" and "planning". The variable "planning" is also a particularly important managerial competency considering the significance in the Fisher linear discriminant analysis and the results of its partial least squares variant. Although the fundamental property of dataset remains unchanged, in some sense the selected outcomes seems to be diverse from the results given by Királ'ová and Malec (2014), often due to the fact that many competencies of the preliminary study are subsets of the ones in current work. Outstanding distinction was revealed at "electronic communication" and "listening and active listening (expression of interest on partner)" of communication ones particularly caused by the different variance and covariance structures within collinear sets and using the regularization approach in the preliminary study. "Electronic communication" competency can be perceived as usual knowledge in the current development of information technologies.

We infer that the partial least squares variant of LDA is a powerful yet simple way to analyse questionnaire survey data, especially in situations covering mutual comparison of results with the standard Fisher linear discriminant analysis and considering the analytical (resp. smooth) paths of the outcomes. In the light of various accreditation scenarios the individual results carry important information for human resource managers, university leadership and staff, employers as well as students and graduates considering careers in the tourismoriented organizations in order to understand the differences between bachelor and master requirements as a part of workplace characteristics and to focus on the most important 
issues of the practical outcomes with enhancing their evaluation. The future studies can be oriented more broadly as considering the differences between general and specific competencies in various economy sectors.

\section{Appendix}

Notation. Assume $X$ is the data matrix of type $(n, p)$ centred by individual columns, which originates as a realization of $n$ observations on $p$ variables. In our study, such observations (vectors in $R^{p}$ ) are generally divided into two sets of data by $n_{1}$ and $n_{2}$ frequencies. We define the between-sets covariance matrix $B$ and the pooled within-sets covariance matrix $W$ in the standard way (Krzanowski, 2000, p. 295). Matrices $B$ and $W$ are both the symmetric and positive semidefinite. The matrix $W$ is considered regular.

\section{Eigenvalue problem}

The algebraic description of functional relation among LDA and its partial least squares variant is derived in accordance to the standard algorithm using linear combinations of original variables (Barker and Rayens, 2003; Carroll and Green, 1976, pp. 278-285; Krzanowski, 2000, pp. 294-306). We solve the optimization task dependent on a parameter $\delta \in\langle 0,1\rangle$

$$
\max _{\mathbf{a} \in R^{p}} \frac{\mathbf{a}^{\prime}(\delta) B \mathbf{a}(\delta)}{\mathbf{a}^{\prime}(\delta) W(\delta) \mathbf{a}(\delta)},
$$

where $W(\delta)=(1-\delta) W+\delta I$ and $I$ is the identity matrix. At $\delta=0$ this term corresponds to the definition of standard Fisher linear discriminant analysis problem and the boundary point $\delta=1$ provides for the plsLDA solution.

Using the Lagrange method, the stationary solution of (1) is given by a generalized eigenvalue problem of the form $B a(\delta)=\lambda(\delta) W(\delta) \boldsymbol{a}(\delta)$ with eigenvalues $\lambda(\delta)$ and corresponding eigenvectors $\boldsymbol{a}(\delta)$ - coefficients of linear combinations (Krzanowski, 2000, p. 298). The generalized eigenvalue problem can be solved either by Cholesky decomposition or using a square root of matrix as a symmetric standard task. In our two-set case, matrix $B$ has a rank of 1 . The symmetric task has the only one simple eigenvalue $\lambda(\delta)$ (of multiplicity 1 ) which is nonzero with corresponding eigenvector $\boldsymbol{a}(\delta)$.

According to the works of Janovská, Janovský and Tanabe (2008), Janovská and Janovský (2010) and Harville (1997), p. 235, theorem 21.9.1, the elements of a symmetric standard eigenvalue problem corresponding to task (1) are analytical (thus also smooth) functions on interval $\langle 0,1\rangle$. If eigenvector satisfies the selected initial condition, then the analytical paths $(\lambda(\delta), \boldsymbol{a}(\delta))$ are determined uniquely on $\langle 0,1\rangle$.

\section{Short formulas}

Considering the example of the two-set Fisher linear discriminant analysis, the final expressions can easily be stated in short computational formulas. Moreover, we take into account our special case of original data, where $n_{1}=n_{2}$. 
Because the only one nonzero eigenvalue can be generally expressed as a trace of decomposed symmetric matrix, we represent such eigenvalue using Mahalanobis squared distance

$$
\frac{n}{4}\left(\overline{\mathbf{x}}_{1}-\overline{\mathbf{x}}_{2}\right)^{\prime} W^{-1}(\delta)\left(\overline{\mathbf{x}}_{1}-\overline{\mathbf{x}}_{2}\right),
$$

where $\overline{\mathbf{x}}_{i}$ denotes the mean vector of $i$-th set. Once again, the boundary points of parameter $\delta \in\langle 0,1\rangle$ correspond to the Fisher discriminant analysis problem and the plsLDA solution. The expression (2) is the Hotelling's $t^{2}$ statistics (Krzanowski, 2000, p. 327).

The elements of eigenvectors can be expressed by term

$$
W^{-1}(\delta)\left(\overline{\mathbf{x}}_{1}-\overline{\mathbf{x}}_{2}\right)
$$

of unit norm.

Because on the whole interval $\langle 0,1\rangle$ the pooled within-sets covariance matrix is regular, then from (Janovská, Janovský and Tanabe, 2008) it is directly seen that the inverse matrix $W^{-1}(\delta)$ is an analytical function of parameter $\delta$ as well as the terms (2) and (3).

\section{References}

Act No. 137/2016 Coll. of 1September 2016, amending Act No. 111/1998 Coll. on Higher Education Institutions. Statute book of the Czech Republic.

Azevedo, A., Apfelthaler, G., Hurst, D. (2012). Competency Development in Business Graduates: An Industry-Driven Approach for Examining the Alignment of Undergraduate Business Education with Industry Requirements. The International Journal of Management Education, 10(1), 12-28, https://doi.org/10.1016/j.jime.2012.02.002

Balcar, J., Janíčková, L., Filipová, L. (2014). What General Competencies are Required from the Czech Labour Force? Prague Economic Papers, 23(2), 250-265, https://doi. org/10.18267/j.pep.483

Barker, M., Rayens, W. (2003). Partial Least Squares for Discrimination. Journal of Chemometrics, 17(3), 166-173, https://doi.org/10.1002/cem.785

Belz, H., Siegrist, M. (2001). Kursbuch Schlüsselqualifikationen. (Key Qualification Course). Freiburg i. Br.: Lambertus.

Boyatzis, R. E. (1982). The Competent Manager: A Model for Effective Performance. New York: John Wiley \& Sons. ISBN 978-0471090311.

Brown, P., Lauder, H. (1996). Education, Globalisation and Economic Development. Journal of Education Policy, 11(1), 1-25.

Čadil, J. (2011). Analýza nákladů veřejných rozpočtů na středního nezaměstnaného. (Analysis of Public Budget Costs for the Average Unemployed) Retrieved from: http://server. universium.cz/publikace/10_analyza_nakladu_ver_rozpoctu_stredni_nezamestnany.pdf

Carroll, J. D., Green, P. E. (1976). Mathematical Tools for Applied Multivariate Analysis. New York: AP Academic Press.

CEDEFOP (2014), Briefing Note - 9087 EN. Skill Mismatch: More than Meets the Eye. Skill Deficits Do Not Cause Unemployment; Europe's Most Talented Workforce Is Being Wasted. Cat. No: TI-BB-14-002-EN-N. Centre for the Development of Vocational Training, Thessaloniki, Greece. 
Chand, M., Katou, A. A. (2007). The Impact of HRM Practices on Organizational Performance in the Indian Hotel Industry. Employee Relations, 29(6), 576-594, https://doi. org/10.1108/01425450710826096

CZSO (2014). Czech Statistical Office - Register of Economic Subjects (in Czech). Retrieved from: http://apl.czso.cz/irsw/dotaz.jsp

CZSO (2015). Czech Statistical Office - Main Indicators of the National Economy and Tourism in the Czech Republic in 2003-2014. Retrieved from: https://www.czso.cz/csu/czso/ tsa_main_indicators_of_the_national_economy_and_tourism_in_the_czech_republic

Drucker, P. (1993). Post-Capitalist Society. London: Harper Collins.

EC (2006). Proposal for a Recommendation of the European Parliament and of the Council on the Establishment of the European Qualifications Framework for Lifelong Learning. Brussels: European Commission.

EC (2007). The Key Competencies for Lifelong Learning - A European Framework. Brussels: European Commission.

English, D., Manton, E., Sami, A. R., Dubey, A. (2012). A Comparison of the Views of College Business Graduate and Undergraduate Students on Qualities Needed in the Workplace. College Student Journal, 46(2), 427-435.

Estenson, J. D. (1999). Alignment of Employer and Faculty Expectations of Student Communication Competencies: A Collaborative Approach to Business Communication Curriculum Development. In: Allied Academies International Conference, Proceedings of the Academy of Educational Leadership 4(2), Las Vegas, U.S., 16-27.

EURODATA (2014). European Company Database: EURODATA Module. Retrieved from: http:// www.hbi.cz/eurodata/index.php?Lang=en

Flynn, T. (2014). Do They Have What It Takes? A Review of the Literature on Knowledge, Competencies, and Skills Necessary for Twenty-First-Century Public Relations Practitioners in Canada. Canadian Journal of Communication, 39(3), 361-384, https://doi.org/10.22230/ cjc.2014v39n3a2775

Harville, D. A. (1997). Matrix Algebra from a Statistician's Perspective. New York: Springer-Verlag. ISBN 978-0-387-94978-9.

Hossain, M. Z. (2011). The Use of Box-Cox Transformation Technique in Economic and Statistical Analyses. Journal of Emerging Trends in Economics and Management Sciences, 2(1), 32-39.

Hruška, J. (2013). Počet nezaměstnaných absolventů stoupá. (The Number of Unemployed Graduates is Rising) Retrieved from: http://www.vysokeskoly.cz/clanek/ pocet-nezamestnanych-absolventu-stoupa

Janovská, D., Janovský, V., Tanabe, K. (2008). An Algorithm for Computing the Analytic Singular Value Decomposition. World Academy of Science, Engineering and Technology, 2(11), 115-120.

Janovská, D., Janovský, V. (2010). The Analytic SVD: On the Non-Generic Points on the Path. Electronic Transactions on Numerical Analysis, 37, 70-86.

Kalina, J. (2012). On Multivariate Methods in Robust Econometrics. Prague Economic Papers, (21)1, 69-82, https://doi.org/10.18267/j.pep.411

Kejhová, H. (2011). Jaký obor volit, aby student neskončil na úřadu práce. (What Field of Study Should be Selected to Avoid Entering the Labour Office) Hospodářské noviny, 7. 3. 2011, 23. Retrieved from: http://www.nuov.cz/vip2/ jaky-obor-volit-aby-student-neskoncil-na-uradu-prace 
Kessler, R., Strasbourg, L. A. (2005). Competency-Based Resumes. Franklin Lakes: Career Press. ISBN 978-1564147721.

Kessler, R. (2006). Competency-Based Interviews. Franklin Lakes: Career Press.

Királ'ová, A., Malec, L. (2014). Communication and Managerial Competencies as a Prerequisite for Employability of Graduates in Tourism. In: The 24th International Business Information Management Association Conference, Milan, Italy, November 6-7, 477-487.

Knight, P., Yorke, M. (2004). Learning, Curriculum and Employability in Higher Education. London: Routledge Farmer. ISBN 9780415303422.

Krzanowski, W. J. (2000). Principles of Multivariate Analysis: A User's Perspective. (2nd Ed.). Oxford: University Press. ISBN 9780198507086.

Kubík, R. (2015). What Is the Real Effect of Schooling on Economic Growth? Prague Economic Papers, 24(2), 125-135, https://doi.org/10.18267/j.pep.504

Mahembe, B., Engelbrecht A. S. (2014). A Preliminary Study to Assess the Construct Validity of a Cultural Intelligence Measure on a South African Sample. SA Journal of Human Resource Management, 12(1), 1-8, https://doi.org/10.4102/sajhrm.v12i1.558

Malec, L., Malec, M. (2013). Application of Two-Set Multivariate Statistical Methods to the Czech Republic Arrival Tourism Data. In: The 7th International Days of Statistics and Economics, Prague, Czech Republic, September 19-21, pp. 937-946.

Malec, L. (2013). On the Multivariate Processing of Rank-Deficient Tourism Data. European Journal of Tourism, Hospitality and Recreation, 4(3), 181-203.

Malec, L. (2015). Analytical Paths of Fisher Linear Discriminant Analysis: A Method for Processing Tourism Data. In: 33rd International Conference Mathematical Methods in Economics, Cheb, Czech Republic, September 9-11, 491-495.

Malec, L. (2016). Some Remarks on the Functional Relation between Canonical Correlation Analysis and Partial Least Squares. Journal of Statistical Computation and Simulation, 86(12), 2379-2391, https://doi.org/10.1080/00949655.2015.1110821

Ngamsom, B. (2001). The Impact of a Bundle of Travel Determinants on Repeat Visitation: An Exploratory Study of Tourism in Thailand. PhD. Thesis, Oklahoma State University, USA.

Nilsson, S. (2010). Enhancing Individual Employability: The Perspective of Engineering Graduates. Education + Training, 52(6/7), 540-551, https://doi. org/10.1108/00400911011068487

OECD (2013). Education at a Glance 2013: OECD Indicators. Retrieved from: http://dx.doi. org/10.1787/eag-2013-en

Orazem, P. F., Vodopivec, M. (1997). Value of Human Capital in Transition to Market: Evidence from Slovenia. European Economic Review, 41(3), 893-903, https://doi.org/10.1016/ s0014-2921(97)00046-9

Pérez-Enciso, E. M., Tenenhaus M. (2003). Prediction of Clinical Outcome with Microarray Data by a Partial Least Squares Discriminant Analysis (PLS-DA) Approach. Human Genetics, 112(5-6), 581-592.

Ramanathan, U., Ramanathan, R. (2013). Investigating the Impact of Resource Capabilities on Customer Loyalty: A Structural Equation Approach for the UK hotels Using Online Rating. Journal of Services Marketing, 27(5), 404-415, https://doi.org/10.1108/ jsm-12-2011-0186

Rankin, N. (2004). The New Prescription for Performance: The 11th Competency Benchmarking Survey. Competency and Emotional Intelligence Benchmarking Suplement 2004-2005. London: IRS. 
Schroder, H. M. (1989). Managerial Competence: The Key to Excellence: A New Strategy for Management Development in the Information Age. London: Kendall \& Kent Publications.

Seaks, T. G., Layson, S. K. (1983). Box-Cox Estimation with Standard Econometric Problems. The Review of Economics and Statistics, 65(1), 160-164, https://doi.org/10.2307/1924424

Sinz, E. J. (2009). Accreditation between Strengthening Competitiveness and Strengthening Bureaucracy - State of the art and Critical Comments. In: Winter, R. (Ed.), Business \& Information Systems Engineering, 4, 332-334.

Smrčka, L., Arltová, M., Schönfeld, J. (2011). Factual and Mathematical Analysis of Impacts of the Economic Crisis on Tourism in the Czech Republic. International Journal of Mathematical Models and Methods in Applied Sciences, 6(5), 1118-1126.

Spitzberg, B. H. (1988). Communication Competence: Measures of Perceived Effectiveness. In: Tardy, C. H. (Ed.), A Handbook for the Study of Human Communication, (67-105). Norwood: Ablex.

Stewart, T. A. (1997). Intellectual Capital: The New Wealth of Organizations. London: Nicholas Brealey.

Van Dyne, L., Ang, S., Koh, C. (2008). Development and Validation of the CQS: The Cultural Intelligence Scale. In: Ang, S. and Van Dyne, L. (Eds.), Handbook on Cultural Intelligence: Theory, Measurement and Applications, (16-38). New York: M.E. Sharpe.

Wegelin, J. A. (2000). A Survey of Partial Least Squares (PLS) Methods, with Emphasis on Two-Block Case. Technical Report No. 371, University of Washington, Seattle, USA.

Woodruffe, C. (1992). What is Meant by Competency? In: Boam, R. and Sparrow, P. (Eds.), Designing and Achieving Competency? (pp. 16-30). London: McGraw-Hill International. 